\title{
Locking plate versus circular external fixator as a definitive external fixator in the treatment of open distal tibia fractures: a retrospective study
}

wei chen ( 175gkcw@xmu.edu.cn )

Dongnan hospital of xiamen university $₫$ school of medicine $₫$ Xiamen university zhangxin chen

Dongnan hospital of xiamen university $₫$ school of medicine $₫$ Xiamen university cong zhang

Dongnan hospital of xiamen university $₫$ school of medicine $₫$ Xiamen university mengyuan wang

Dongnan hospital of xiamen university $₫$ school of medicine $\$ Xiamen university wenbin $\mathrm{xu}$

First Affiliated Hospital of Xiamen University, school of medicine, xiamen university

\section{mingming gao}

Dongnan hospital of xiamen university $₫$ school of medicine $\$ Xiamen university zhenqi ding

Dongnan hospital of xiamen university $₫$ school of medicine $\$ Xiamen university

\section{Research Article}

Keywords: open distal tibia fractures, Locking plate, circular external fixator, a retrospective study

Posted Date: February 28th, 2022

DOI: https://doi.org/10.21203/rs.3.rs-1360629/v1

License: (9) This work is licensed under a Creative Commons Attribution 4.0 International License. Read Full License 


\section{Abstract}

Background: Local soft tissue contusion, bone exposure, and wound contamination are often accompanied by open distal tibia fractures. External fixation is the most commonly used temporary or terminal fixation treatment. The locking plate as external stent fixation and circular external fixator has become the major technical surgery for the definitive treatment of open distal tibia fractures. Both can achieve reliable fixation of fracture ends that do not cross the ankle joint and promote fracture healing and soft tissue repair. This study aimed to compare the functional and radiological outcomes of external locking plate and circular external fixator in the treatment of open distal tibia fractures.

Methods: Emergency operation patients treated for open distal fractures in $\nabla$ segment of the tibia (all were extra-articular fractures) between October 2016 and October 2020 were retrospectively investigated. Patients were divided by a random number table into a locking plate external fixation treatment group

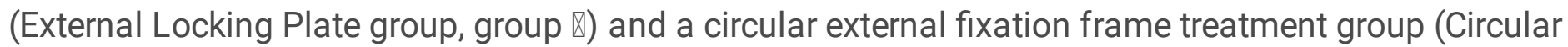

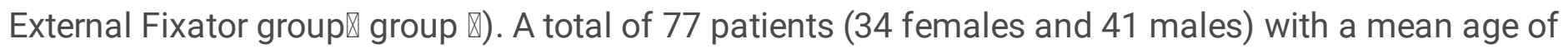
$31.60 \pm 10.92$ (range: 18-60) years were evaluated. Fractures were graded according to Gustilo and AO/ASIF classification, respectively. In the External Locking Plate group (31 cases), Gustilo type II 18 and Gustilo type IIIA 13. Then according to the AO/ASIF classification, 14 by type $42-\mathrm{B}, 14$ by $42-\mathrm{C}$, and 3 by 43-A; While in the Circular External Fixator group (46 patients), there were Gustilo type II (23 patients) and Gustilo type IIIA (23 patients), type 42-B (25 patients), type 42-C (17 patients), and type 43-A (4 patients). The general data such as gender, age, and cause of injury were recorded and compared between the two groups. The clinical and radiographic outcomes were retrospectively evaluated, such as the surgical time, the surgical surface notch of the external fixative object, postoperative wound infection rate, incision infection rates, bone healing time, nonunion rate, secondary surgery rate, the number of angulation degrees in the fracture area at the last X-ray, and the Johner-Wruhs functional score of the ankle at the last follow-up.

Results: All patients were followed up for a mean period of $13.71 \pm 2.61$ months (range 9-18 months). The operative time was $66.90 \pm 5.37$ ) minutes and $84.74 \pm 6.72$ ) minutes in the External Locking Plate group and Circular External Fixator group, respectively. The patients had an external fixation object surface notch of $(2.00 \pm 0.21) \mathrm{cm}$ and $(5.30 \pm 1.10) \mathrm{cm}$, respectively. In incision infection rates, eight nail infections in the External Locking Plate group (8 / 228) and 28 nail infections (28 / 365) were diagnosed in the Circular External Fixator group. For the Johner-Wruhs functional score of the ankle at the last follow-up, 26 superior and 4 superior and 1 inferior in the External Locking Plate group; 96.7\% (30 / 31) superior and 24 superior and 17 inferior and 5 inferior in the Circular External Fixator group; 89.1\% (41 / 46) superior and $3.67 \pm 1.38$ (1.8-5.4) degrees in the Circular External Fixator group at the last X-ray fracture zone compared with $6.04 \pm 2.13$ (3.6-9.2) degrees in the External Locking Plate group. The degree of deformity angulation was small. All of the above indexes showed statistically significant differences between the two groups. There were no significant differences between the two groups in bone healing time, nonunion rate, secondary surgery rate, and postoperative wound infection rate. In the External Locking Plate group, three patients required adjustment of plate height or position at the time of 
secondary surgery, and one patient was changed to a combined external fixator; while in the Circular External Fixator group and 2 patients had nonunion, all of whom underwent two-stage bone grafting, and 3 had deep wound infection and two-stage augmentation procedures in which one to two fixation pins were adjusted for each intraoperative period and then healed via skin flap and bone grafting.

Conclusion: Both the External Locking Plate group and the Circular External Fixator group effectively promoted bone and soft tissue repair as the terminal treatment for open fractures of the distal tibia. The former group has some advantages such as simple operation, low notch, low pin eye infection rate, and more excellent preservation of ankle function, but there is a residual deformity or anterior tibial soft tissue necrosis after surgery, infection requiring secondary expansion, and flap repair when surgery is performed, greater adjustability, and operational adaptability of the annular outer shelf.

\section{Introduction}

The open distal tibia fractures are often accompanied by local soft tissue contusion, bone exposure, and wound pollution, and easy to cause complications such as bone nonunion, which is a problem worthy of attention. The main technical difficulties are infection, soft tissue and bone defect, angular deformity, and leg length difference [1]. In the United States, the retrospective analysis of national inpatient samples from 2000 to 2011 found that the early amputation rate of open tibial fracture was $2.2 \%$ [2]. Open fractures of the distal tibia generally have a high risk of deep or superficial infection, leading to repeated surgery, especially in low- and middle-income countries [3]. In principle, the treatment for open distal tibia fractures is basically to control infection, preserve the ankle's mobility as much as possible, and quickly return to the previous activity state [4]. At present, the typical treatment methods include internal fixation, external locking plate, simple external fixator, external fixator combined with plate and screw internal fixation, etc. [5-9]. The infection rate of internal fixation such as the intramedullary nail, in the open tibial fracture, is as high as $31.5 \%$ [10], of which is mainly caused by Staphylococcus aureus. External fixation is often the preferred treatment for an open fracture and the most commonly used temporary or terminal fixation. However, there are many kinds of external fixation, and most of them have to cross the joint. External locking plate and circular external fixation have become the leading technical surgery for the definitive treatment of open fracture because of realizing reliable fixation of fracture ends, not cross the ankle joint, promote fracture healing and soft tissue repair [11, 12]. At present, there are few relevant studies and comparative studies. The purpose of our study was to evaluate the effect of external locking plate and circular external fixator in the treatment of open distal tibia fractures to achieve a reasonable cure rate.

\section{Patients And Methods}

This retrospective study included 77 patients with open fractures of the distal tibia who met our selection criteria and were treated at the author's institution from October 2016 to October 2020. 
Inclusion criteria: open fracture of distal $₫$ segment of the tibia (Gustilo $\nabla$ or $\nabla A$ ) with emergency surgical cases or Case of secondary operation, fracture according to AO / ASIF classification, including 42-B, 42-C, and 43-A (all extra-articular fractures), aged $18-60$ years.

Exclusion criteria include any debilitating diseases, smoking, neurological and vascular injury, severe medical complications such as diabetes, osteoporosis, arteriosclerosis obliterans. Other fractures of the lower extremities, with bone and soft tissue defects, the fracture cannot heal the wounds together at the first stage (skin flap repair is needed).

According to the patients who met the inclusion criteria at the time of admission, there were 41 males and 34 females, with an average age of $31.60 \pm 10.92$ years. The results were objectively graded according to

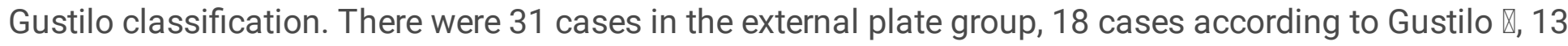
cases according to Gustilo $\otimes A, 14$ cases according to AO / ASIF, 14 cases of 42-B, 14 cases of 42-C, and 3 cases of $43-A$; There were 46 cases in the ring frame fixation group, 23 cases of Gustilo $\nabla$ and 23 cases of Gustilo $\otimes A$. According to AO / ASIF classification, there were 25 cases of 42-B type, 17 cases of 42-C type and 4 cases of 43-A type. All patients obtained informed consent before operation.

\section{Operative technique}

All operations were performed under supine general or epidural anesthesia. The tourniquet is routinely used until the debridement is completed, the open fracture wound is on the original wound, or the surgical incision is extended, the wound is cleaned, the necrotic tissue is removed, and the fracture end is pried and reset under direct vision. After the $\mathrm{C}$-arm fluoroscopy reduction is satisfactory, the external locking plate or ring external fixator is fixed. After the wound is sutured, the tourniquet is deflated. All surgeries were performed by the same orthopedic surgeon (Wei Chen). In the first method, the locking plate was placed externally (group I, $n=31$ ). The plate used was produced by Xiamen Dabo company. According to the amount of residual bone in the distal tibia, the L plate in the distal tibia of the LISS plate in the distal femur was selected, and the latter was preferred. In the second method, the wounds could be sutured in one stage using the circular external fixator fixation technology (Group II, $n=46$ ). The negative pressure drainage tube was used for 3 days.

\section{Post-operative regimen and patient's evaluation}

After 72 hours, the patient has removed the negative pressure drainage tube, rechecked the blood inflammation index, confirmed that the wound had no signs of infection, received education on how to clean the external fixator frame and how to deal with the wound dressing, and was discharged from the hospital. They were instructed to attend the first follow-up on postoperative day 7 . In this visit, both two groups of patients observed the wound, took X-rays for imaging observation, and then tried to deal with the situation. Then, the positive and lateral $\mathrm{X}$-ray radiographic examination was carried out at the $4 \mathrm{~W}, 3 \mathrm{M}$, $6 \mathrm{M}$, and $1 \mathrm{Y}$ follow-up, respectively, to evaluate varus deformity at the fracture end and the deformity 
angle. When the angular deformity in the fracture area was found, the annular outer frame could be adjusted in time to ensure that the alignment of the fracture area was good. The ankle joint surface was horizontal, while the external steel plate was accepted when the deformity was accepted. At the same time, evaluate the new bone quality at the proximal distraction site, check the stability of the stent, and deal with needle tract infection (if any). In case of nail canal infection, after the routine antibiotic treatment is ineffective, pull out the infected nail and judge the stability of the ring frame. If the stability is good, disinfect and change the dressing. If the stability is poor, deal with it by changing the position of the nail canal. At the same time, the follow-up time of patients undergoing secondary surgery shall be extended accordingly. Under the condition of tolerance, it is allowed for some patients to start loading. Then, bone After fracture healing, the frame was removed based on outpatient sedation, and the brace below the knee was used to protect it for 8 weeks. At the same time, the patients were guided to carry out joint function training.

Fracture healing time, external fixator use time, complications, and functional results were recorded according to the criteria described by Johner $\mathrm{R}$ [13]. Patients were also asked to complete the NRS [14] pain score between 1 and 10 to provide their acceptance and tolerance of the whole operation. The lower the score, the more acceptable.

\section{Statiscal analysis}

The results were expressed by means and standard deviation. The two mean values were compared by ttest, and the categorical variables were compared by chi-square test. $P$ values $<0.05$ were considered significant.

\section{Results}

In terms of the impact of different variables on the results, there was no significant statistical significance in the comparison of general factors such as age, follow-up time, gender, cause of injury, fracture type (Gustilo and AO / ASIF classification), injury site, injury to operation time $(P>0.05)$. All the results of preoperative indicators are summarized in Table 1, indicating that the two groups of patients are comparable. 
Table 1

Patients baseline demographics and procedure characteristics in both groups

\begin{tabular}{|c|c|c|c|c|c|c|c|}
\hline \multicolumn{6}{|l|}{77 patients } & \multirow[t]{2}{*}{ Test } & \multirow{2}{*}{$\begin{array}{l}P \\
\text { value }\end{array}$} \\
\hline \multicolumn{2}{|l|}{ Parameter } & \multicolumn{2}{|c|}{$\begin{array}{l}\text { Group I(n = } \\
31)\end{array}$} & \multicolumn{2}{|c|}{$\begin{array}{l}\text { Group II(n = } \\
46)\end{array}$} & & \\
\hline \multirow[t]{2}{*}{ Age } & Range & \multicolumn{2}{|c|}{$17-54$} & \multicolumn{2}{|c|}{$16-57$} & \multirow[t]{2}{*}{$t=0.601$} & \multirow{2}{*}{$\begin{array}{l}P= \\
0.550\end{array}$} \\
\hline & Mean \pm SD & \multicolumn{2}{|c|}{$31.87 \pm 10.31$} & \multicolumn{2}{|c|}{$33.35 \pm 10.75$} & & \\
\hline \multirow[t]{2}{*}{ Follow-up(months) } & Range & \multicolumn{2}{|c|}{$9-18$} & \multicolumn{2}{|c|}{$10-18$} & \multirow[t]{2}{*}{$t=1.048$} & \multirow{2}{*}{$\begin{array}{l}P= \\
0.298\end{array}$} \\
\hline & Mean \pm SD & \multicolumn{2}{|c|}{$14.10 \pm 2.87$} & \multicolumn{2}{|c|}{$13.46 \pm 2.46$} & & \\
\hline Parameter & & $N$ & $\%$ & $\mathrm{~N}$ & $\%$ & & \\
\hline \multirow[t]{2}{*}{ Gender } & Male & 14 & $45.2 \%$ & 27 & $58.7 \%$ & \multirow[t]{2}{*}{$c^{2}=1.363$} & \multirow{2}{*}{$\begin{array}{l}P= \\
0.243\end{array}$} \\
\hline & Female & 17 & $54.8 \%$ & 19 & $42.3 \%$ & & \\
\hline \multirow[t]{2}{*}{ Cause of injury } & $\begin{array}{l}\text { Traffic } \\
\text { Accident }\end{array}$ & 19 & $61.3 \%$ & 29 & $63.0 \%$ & \multirow[t]{2}{*}{$c^{2}=0.024$} & \multirow[t]{2}{*}{$\begin{array}{l}P= \\
0.876\end{array}$} \\
\hline & Fall Injury & 12 & $38.7 \%$ & 17 & $37.0 \%$ & & \\
\hline \multirow[t]{2}{*}{ Type of Gustilo injury } & Gustilo II & 18 & $58.1 \%$ & 23 & $50 \%$ & \multirow[t]{2}{*}{$c^{2}=0.484$} & \multirow{2}{*}{$\begin{array}{l}P= \\
0.487\end{array}$} \\
\hline & Gustilo IIla & 13 & $41.9 \%$ & 23 & $50 \%$ & & \\
\hline \multirow[t]{3}{*}{ Type of AO/ASIF } & $42-\mathrm{B} \square$ & 14 & $45.2 \%$ & 25 & $54.3 \%$ & \multirow[t]{3}{*}{$c^{2}=0.638$} & \multirow{3}{*}{$\begin{array}{l}P= \\
0.727\end{array}$} \\
\hline & $42-\mathrm{C} \square$ & 14 & $45.2 \%$ & 17 & $37.0 \%$ & & \\
\hline & $43-\mathrm{A}]$ & 3 & $9.6 \%$ & 4 & $8.7 \%$ & & \\
\hline \multirow[t]{2}{*}{ Side affected } & Right & 15 & $48.4 \%$ & 20 & $43.5 \%$ & \multirow[t]{2}{*}{$c^{2}=0.180$} & \multirow{2}{*}{$\begin{array}{l}P= \\
0.671\end{array}$} \\
\hline & Left & 16 & $51.6 \%$ & 26 & $56.5 \%$ & & \\
\hline Injury until operation & Range & 187 & 599 & 202 & 598 & $t=0.489$ & $P=$ \\
\hline & Mean \pm SD & $\begin{array}{l}392 \\
123\end{array}$ & $\begin{array}{l}9 \pm \\
9\end{array}$ & $\begin{array}{l}378 \\
121\end{array}$ & $\begin{array}{l}7 \pm \\
2\end{array}$ & & \\
\hline
\end{tabular}

In the postoperative indicators, all results are summarized in Table 2. Wound infection, nonunion, and fracture healing time had no significant effect between groups I and II $(P>0.05)$. The surface notch, operation time, number of nails, and NRS pain score of external fixation objects in group I were significantly better than those in group II $(P<0.005)$. In terms of needle (or nail) eye infection, there were 8 nail paths in the plate external group (8 / 228) and 28 nail paths in the ring frame fixation group (28 / $365)$, which had a better advantage $(P<0.05)$. In the Johner-Wruhs functional evaluation without followup, the external plate group was excellent in 26 cases, fair in 4 cases, and poor in 1 case. The qualified rate was 96.7\% (30 / 31); In the ring frame fixation group, 24 cases were excellent, 17 were fair, and 5 
were poor. The excellent and good rate was $89.1 \%$ (41 / 46). There was a significant difference between the two groups $(P<0.05)$. Through the last $X$-ray evaluation and measurement, 8 patients in group I had an angular deformity in the fracture area: 4 cases of varus angular deformity, 1 case of valgus angular deformity, 3 cases of forward angular deformity, and the angular degree was $6.04 \pm 2.13^{\circ}\left(3.6-9.2^{\circ}\right)$; In group II, there were 6 cases of angular deformity in the fracture area, including 2 cases of varus angulation, 3 cases of forward angulation and 1 case of backward angulation, with an angle degree of $3.67 \pm 1.38^{\circ}\left(1.8-5.4^{\circ}\right)$.

In group I, one patient underwent bone grafting for nonunion and healed after operation; Two patients with deep infection and one with poor postoperative healing underwent secondary debridement. Due to the influence of surgical operation, the height or position of the steel plate was adjusted, and the wound healed after operation; One patient with skin necrosis and bone exposure needed local flap transfer and combined external fixation. In group II, two patients with nonunion underwent secondary bone grafting. One case had wound infection and recovered after routine antibiotic treatment, and three cases had deep wound infection. After standard antibiotic treatment was ineffective, the secondary wound expansion was performed. During the operation, $1 \sim 2$ fixed needles were adjusted respectively, and then the flap was transplanted and healed.

Figure $1 \mathrm{a} b$

Fig.1 Anteroposterior X-ray films of a 48-year-old male patient with tibia fracture of the right (AO/OTA $43 \mathrm{~A} 2$ type ) caused by falling from height. a,Before the operation, open fracture of distal $\mathbb{\nabla}$ segment of the tibia; b, At 6 months after the operation, the fracture healing was good, and the external fixator with locking plate was in place.

Figure $2 \mathrm{a} b$

Figure 2 Anteroposterior X-ray films of a 59-year-old male patient with tibia fracture of the right (AO/OTA 43A2 type ) caused by trauma. a, Before the operation, open fracture of distal $\otimes$ segment of the tibia; $b$, At 6 months after the operation, the fracture healing was good, and a circular external fixator was in place. 
Table 2

Results among both groups in the study

\begin{tabular}{|c|c|c|c|c|c|c|c|}
\hline \multicolumn{8}{|l|}{ Group I $(n=31)$ Group IIIn = 46! } \\
\hline \multirow[t]{2}{*}{ operation time(min) } & \multirow{2}{*}{$\begin{array}{l}\text { Range } \\
\text { Mean } \pm \\
\text { SD }\end{array}$} & \multicolumn{2}{|c|}{$58-77$} & \multicolumn{2}{|c|}{$79-92$} & \multirow{2}{*}{$\begin{array}{l}t= \\
12.906\end{array}$} & \multirow{2}{*}{$\begin{array}{l}P= \\
0.000\end{array}$} \\
\hline & & \multicolumn{2}{|c|}{$66.90 \pm 5.37$} & \multicolumn{2}{|c|}{$84.74 \pm 6.72$} & & \\
\hline \multirow[t]{2}{*}{ Number of nailing } & \multirow{2}{*}{$\begin{array}{l}\text { Range } \\
\text { Mean } \pm \\
\text { SD }\end{array}$} & \multicolumn{2}{|l|}{$6-8$} & \multicolumn{2}{|c|}{$7-10$} & \multirow[t]{2}{*}{$t=3.044$} & \multirow{2}{*}{$\begin{array}{l}P= \\
0.004\end{array}$} \\
\hline & & \multicolumn{2}{|c|}{$7.35 \pm 0.95$} & \multicolumn{2}{|c|}{$7.93 \pm 0.57$} & & \\
\hline \multirow[t]{2}{*}{ NRS pain scale } & Range & \multicolumn{2}{|l|}{$3-6$} & \multicolumn{2}{|l|}{$3-7$} & \multirow[t]{2}{*}{$t=3.448$} & \multirow{2}{*}{$\begin{array}{l}P= \\
0.001\end{array}$} \\
\hline & $\begin{array}{l}\text { Mean } \pm \\
\text { SD }\end{array}$ & \multicolumn{2}{|c|}{$4.16 \pm 1.10$} & \multicolumn{2}{|c|}{$5.00 \pm 1.01$} & & \\
\hline \multirow{2}{*}{$\begin{array}{l}\text { External fixed object surface } \\
\text { trace }(\mathrm{cm})\end{array}$} & Range & \multicolumn{2}{|c|}{$1.7-2.3$} & \multicolumn{2}{|c|}{$6.7-3.7$} & \multirow[t]{2}{*}{$\begin{array}{l}t= \\
19.802\end{array}$} & \multirow[t]{2}{*}{$\begin{array}{l}P= \\
0.000\end{array}$} \\
\hline & $\begin{array}{l}\text { Mean } \pm \\
\text { SD }\end{array}$ & \multicolumn{2}{|c|}{$2.00 \pm 0.21$} & \multicolumn{2}{|c|}{$5.30 \pm 1.10$} & & \\
\hline \multirow[t]{2}{*}{ Bone healing time(week) } & Range & \multicolumn{2}{|c|}{$20-36$} & $36-$ & & $t=0.749$ & $\begin{array}{l}P= \\
0.457\end{array}$ \\
\hline & $\begin{array}{l}\text { Mean } \pm \\
\text { SD }\end{array}$ & 27.6 & \pm 5.91 & 28.5 & \pm 4.36 & & \\
\hline Postoperative angular degree & Range & $3.6-$ & & $1.8-$ & & $t=2.339$ & $\begin{array}{l}\mathrm{P}= \\
0.032\end{array}$ \\
\hline & $\begin{array}{l}\text { Mean } \pm \\
\text { SD }\end{array}$ & 6.04 & 2.13 & 3.67 & 1.38 & & \\
\hline Postoperative wound infection & Yes & 2 & $6.5 \%$ & 4 & $8.7 \%$ & $c^{2}=0.130$ & $P=$ \\
\hline & No & 29 & $93.5 \%$ & 42 & $91.3 \%$ & & \\
\hline Needle (or nail) channel & Yes & 8 & $3.5 \%$ & 28 & $7.7 \%$ & $c^{2}=4.264$ & $P=$ \\
\hline & No & 220 & $96.5 \%$ & 337 & $92.3 \%$ & & \\
\hline Bone nonunion & Yes & 1 & $3.2 \%$ & 2 & $4.3 \%$ & $c^{2}=0.062$ & $\mathrm{P}=$ \\
\hline & No & 30 & $96.8 \%$ & 44 & $95.7 \%$ & & \\
\hline Re-operation & Yes & 4 & $12.9 \%$ & 5 & $11 \%$ & $c^{2}=0.074$ & $\begin{array}{l}P= \\
0785\end{array}$ \\
\hline & No & 27 & $87.1 \%$ & 41 & $89 \%$ & & \\
\hline Johner-Wruhs score & Good & 26 & $76.4 \%$ & 24 & $52 \%$ & $c^{2}=8.183$ & $P=$ \\
\hline & Fair & 4 & $12.9 \%$ & 17 & $37 \%$ & & \\
\hline & Poor & 1 & $3.2 \%$ & 5 & $11 \%$ & & \\
\hline
\end{tabular}




\section{Discussion}

The treatment of open distal tibia fractures is a challenging problem for orthopedic surgeons. Whether it is an accident injury or falling from a height [15], the open fracture will bring a substantial economic burden to patients and the medical system [16], and because of open fracture, there is still a risk of infection even after debridement [17]. Gustilo classification of open tibial fractures is by far the most significant predictor of nonunion and infection [18]. Gustilo II and IIIA common surgical fixation forms include llizarov external fixator [19], the internal or external fixator [20], interlocking intramedullary nail [21], external fixation in the early stage of open reduction and internal fixation in the late stage [22], MIPPO internal fixation [23], Outcome of rail fixator system [24], combining internal nailing and plate fixation [25], etc. The treatment principles for open fractures of the distal tibia include complete removal of all infected and inactivated tissues, adequate bone alignment, excellent blood supply to the opposite bone end, and stable fixation [26].

Recently a few studies have focused on the comparative treatment of open fractures of the distal tibia with external plate and annular external fixator. Zhang $\mathrm{J}$ et al. [27] proposed the feasibility of ensuring the stability of external fixation of distal tibial fractures through finite element analysis. A. W. Bach et al. [28] pointed out that external fixation for open tibial fractures can reduce the incidence of complications in 1989. Rene K. $\mathrm{m}$ art et al. [29] Used AO plate external fixation for open forearm fractures in 1991, pointed out the advantages of providing stability and convenience to patients. L. J. sun et al. [30] found that the patients in the external fixation group had the advantages of the short operation time, more minor wound complications, and less ankle pain. Xiangfeng HeZ et al. [31] found that the locking plate on the skin has the advantages of minor trauma, lower cost, and shorter hospital stay. Jingwei Zhang et al. [32] pointed out that the external steel plate can even hide the steel plate under the clothes while providing stability due to the low cutting trace of the fixation. In addition, it pointed out that it is a safe and reliable method for treating proximal tibial metaphyseal fractures [33]. Wei Liu et al. [34] biomechanically confirmed that the locking compression plate is flexible as an external fixator. The locking compression plate at the distal femur is better than the locking plate at the distal tibia. It is an external fixator for distal tibial fractures. B. F. H. Ang et al. [35] proved that the external steel plate does not affect the axial and torsional stiffness during fixation. Xu Sheng Qiu et al. [36] pointed out that patients with open fractures with soft tissue loss still have good functional recovery. For the annular external fixator, Muhammad Atif et al. [37] pointed out that the curative effect was acceptable as a primary operation and had the advantage of being adjustable in a retrospective study of 93 cases from the primary trauma center.

In the retrospective study, radical debridement was performed in all open cases, which emphasized that for patients with Gustilo II and IIIA in open fractures of the distal tibia. Considering the patient's comfort and postoperative infection management, group I has apparent advantages over group II in the lower notch and lower nail canal infection rate, including the surface notch of external fixation objects in group I. The number of nail canal infection cases was significantly lower than that in group II $(P<0.005)$. And the way of locking the external steel plate, because there was no internal plant and thorough debridement, the risk of infection was lower, the cutting mark of fixation was lower. It was less bulky than the annular 
external fixator, which would not cause too much trouble to patients in terms of convenience of life [38]. At the same time, from the perspective of surgeons, the operation time in the group I was significantly lower than that in group II $(P<0.05)$, and the operation of external steel plate was simple. In addition, in this study, the clinical scores of Johner-Wruhs were comparable between the two groups without followup. Group I had a significant advantage over group II, indicating that group I could retain ankle function greater extent [39]. In this study, out of concern for patients, all patients were given NRS pain scores to reflect their subjective satisfaction and acceptance of the whole process. Group I was significantly better than the external fixator (Group II) $(P<0.05)$. Considering that the annular external fixator mostly used full needle penetration, it was easy to cause tendon friction and high irritation; because of pain and other discomforts, it is also easy to reduce the range of motion of the ankle joint [40]. At the same time, patients in group I have significant advantages in self-perception.

The angulation degree of the fracture area in the last X-ray examination in group II is smaller than that in group I, and the difference between the two groups is statistically significant, which proves that the ring frame can be easily adjusted after the operation, can avoid the angulation between the fracture area and the ankle joint surface as far as possible, and has more robust adjustability and adaptability. In group I, 3 patients needed to adjust the height or position of the plate during the second operation; 1 patient with skin flap had to use the combined external fixator. In group II, 5 patients underwent flap and bone graft healing after adjusting only 1-2 fixing needles in the second stage expansion. The results suggest that surgeons may prioritize using an annular external fixator when judging the prognosis risk of patients through Gustilo classification (secondary flap transplantation and secondary expansion may be required), which can facilitate the postoperative adjustment of patients.

\section{Conclusions}

The External Locking Plate group and Circular External Fixator group are used as the definitive treatment of distal tibial open fractures, which could effectively promote the repair of bone and soft tissue in distal tibial open fractures (Gustilo II and IIIA; AO / ASIF, 43-A). The former has the advantages of simple operation, low notch, low needle eye infection rate, and greater preservation of ankle function. However, when there are residual deformities, anterior tibial soft tissue necrosis, an infection that requires secondary expansion and flap repair, the annular outer frame has more robust adjustability and operation adaptability.

\section{Declarations}

\section{Ethics approval and consent to participate}

This study was performed in accordance with the Declaration of Helsinki as revised in 2008 . All protocols was authorized by the Ethics and research committee at The Affiliated Dongnan Hospital of Xiamen University. Informed consent has been obtained from all subjects or their legal guardians. 


\section{Consent for publication}

Not applicable, as no identifying personal information is included inthis manuscript. All patients or their families signed the informed consent before surgery and provided the consent to publish and report individual clinical data.

\section{Competing interests}

The authors declare that they have no competing interests.

\section{Funding}

This work was supported by the Military logistics research project (CNJ16C013), the role of which included design of the study and English editing. The role of which included design of the study and interpretation of data supported by Zhangzhou natural science foundation projects in 2021 (ZZ2021J45), the role of which included providing research equipment support and equipment wastage.

\section{Availability of data and materials}

The data and materials are available from the medical records department of The Affiliated Dongnan Hospital of Xiamen University. The datasets used and analysed during the current study are available from the corresponding author on reasonable request.

\section{Author's Contributions}

Zhenqi Ding and Wei Chen designed the study, modified and approved the final version of the manuscript. Zhangxin Chen wrote the first draft of the manuscript. Zhang Cong, Mengyuan Wang, Wenbin Xu, mingming gao,collected, analyzed and interpreted the data. All authors have read and approved the manuscript.

\section{Acknowledgements}

We would like to thank subjects included in the current study and all physicians and nurses involved in the management of the patients.

\section{Any restrictions to use by non- academics}

For commercial use and modifications please contact the corresponding author. 


\section{References}

1. Asad WA, Younis MHS, Ahmed AF, Ibrahim T,(2018) Open versus closed treatment of distal tibia physeal fractures: a systematic review and meta-analysis. Eur J Orthop Surg Traumatol 28:503-509. DOI 10.1007/s00590-017-2062-1

2. Mundy LR, Truong T, Shammas RL, Cunningham D, Hollenbeck ST, Pomann GM, Gage MJ,(2021) Amputation Rates in More Than 175,000 Open Tibia Fractures in the United States. Orthopedics 44:48-53. DOI 10.3928/01477447-20201202-03

3. Whiting PS, Galat DD, Zirkle LG, Shaw MK, Galat JD,(2019) Risk Factors for Infection After Intramedullary Nailing of Open Tibial Shaft Fractures in Low- and Middle-Income Countries. J Orthop Trauma 33:e234-e239. DOI 10.1097/bot.0000000000001441

4. Park J, Yang KH,(2012) Treatment of an open distal tibia fracture with segmental bone loss in combination with a closed proximal tibia fracture: a case report. Archives of orthopaedic and trauma surgery 132:1121-1124. DOI 10.1007/s00402-012-1523-6

5. Sun DD, Lv D, Zhou K, Chen J, Gao LL, Sun ML,(2021) External fixator combined with three different fixation methods of fibula for treatment of extra-articular open fractures of distal tibia and fibula: a retrospective study. BMC Musculoskelet Disord 22:1

6. Zelle BA, Bhandari M, Espiritu M, Koval KJ, Zlowodzki M,(2006) Treatment of distal tibia fractures without articular involvement: a systematic review of 1125 fractures. J Orthop Trauma 20:76-79. DOI 10.1097/01.bot.0000202997.45274.a1

7. Sathiyakumar V, Thakore RV, Ihejirika RC, Obremskey WT, Sethi MK,(2014) Distal tibia fractures and medial plating: factors influencing re-operation. International orthopaedics 38:1483-1488

8. Quinnan SM,(2016) Definitive Management of Distal Tibia and Simple Plafond Fractures With Circular External Fixation. J Orthop Trauma 30 Suppl 4:S26-S32. DOI 10.1097/bot.0000000000000694

9. Wysocki RW, Kapotas JS, Virkus WW,(2009) Intramedullary nailing of proximal and distal one-third tibial shaft fractures with intraoperative two-pin external fixation. J Trauma 66:1135-1139. DOI 10.1097/TA.0b013e3181724754

10. Toro-Aguilera Á, Zuriarrain SW, Masdeu MG, Sayol RR, Billi AM, Carrera I, de Caso J,(2021) Risk factors for infection in fixation of distal tibia fractures. Injury 52 Suppl 4:S104-S108. DOI 10.1016/j.injury.2021.02.085

11. Fadel M, Ahmed MA, Al-Dars AM, Maabed MA, Shawki H,(2015) Ilizarov external fixation versus plate osteosynthesis in the management of extra-articular fractures of the distal tibia. International orthopaedics 39:513-519. DOI 10.1007/s00264-014-2607-4

12. Mei ZF, Fan SW, Zhao FD, Wang CY, Liu JH, Shan Z,(2014) [Locking plate external fixator for the treatment of middle and distal tibial fractures]. Zhongguo gu shang $=$ China journal of orthopaedics and traumatology 27:458-460 
13. Johner R, Wruhs $0,(1983)$ Classification of tibial shaft fractures and correlation with results after rigid internal fixation. Clin Orthop Relat Res:7-25

14. Ferreira-Valente MA, Pais-Ribeiro JL, Jensen MP,(2011) Validity of four pain intensity rating scales. Pain 152:2399-2404. DOI 10.1016/j.pain.2011.07.005

15. Schade AT, Hind J, Khatri C, Metcalfe AJ, Harrison WJ,(2020) Systematic review of patient reported outcomes from open tibia fractures in low and middle income countries. Injury 51:142-146. DOI 10.1016/j.injury.2019.11.015

16. Schade AT, Khatri C, Nwankwo H, Carlos W, Harrison WJ, Metcalfe AJ,(2021) The economic burden of open tibia fractures: A systematic review. Injury 52:1251-1259. DOI 10.1016/j.injury.2021.02.022

17. Tribble DR, Lewandowski LR, Potter BK, Petfield JL, Stinner DJ, Ganesan A, Krauss M, Murray CK, (2018) Osteomyelitis Risk Factors Related to Combat Trauma Open Tibia Fractures: A Case-Control Analysis. J Orthop Trauma 32:e344-e353

18. Thakore RV, Francois EL, Nwosu SK, Attum B, Whiting PS, Siuta MA, Benvenuti MA, Smith AK, Shen MS, Mousavi I, Obremskey WT, Sethi MK,(2017) The Gustilo-Anderson classification system as predictor of nonunion and infection in open tibia fractures. Eur J Trauma Emerg Surg 43:651-656. DOI 10.1007/s00068-016-0725-y

19. Makhdoom AU, Shaikh BJ, Baloch RA, Malah HR, Tunio ZH, Jokhio MF,(2020) Management Of Segmental Fracture Of Tibia Treated By llizarov External Fixation. J Ayub Med Coll Abbottabad 32:291-294

20. Stannard JP, Finkemeier CG, Lee J, Kregor PJ,(2008) Utilization of the less-invasive stabilization system internal fixator for open fractures of the proximal tibia: a multi-center evaluation. Indian $\mathrm{J}$ Orthop 42:426-430

21. Pinto D, Manjunatha K, Savur AD, Ahmed NR, Mallya S, Ramya V,(2019) Comparative study of the efficacy of gentamicin-coated intramedullary interlocking nail versus regular intramedullary interlocking nail in Gustilo type I and II open tibia fractures. Chin J Traumatol 22:270-273

22. Albright PD, MacKechnie MC, Roberts HJ, Shearer DW, Padilla Rojas LG, Segovia J, Quintero JE, Amadei R, Baldy Dos Reis F, Miclau T, 3rd,(2020) Open Tibial Shaft Fractures: Treatment Patterns in Latin America. J Bone Joint Surg Am 102:e126. DOI 10.2106/jbjs.20.00292

23. Galal $S,(2018)$ Minimally invasive plate osteosynthesis has equal safety to reamed intramedullary nails in treating Gustilo-Anderson type I, II and III-A open tibial shaft fractures. Injury 49:866-870. DOI 10.1016/j.injury.2018.03.008

24. Lakhani A, Singh $D$, Singh $R$,(2014) Outcome of rail fixator system in reconstructing bone gap. Indian J Orthop 48:612-616

25. Liu H, Wu J, Lin D, Lian K, Luo D,(2019) Results of combining intramedullary nailing and plate fixation for treating segmental femoral fractures. ANZ J Surg 89:325-328. DOI 10.1111/ans.15050

26. Sohn OJ, Kang DH,(2011) Staged protocol in treatment of open distal tibia fracture: using lateral MIPO. Clinics in orthopedic surgery 3:69-76. DOI 10.4055/cios.2011.3.1.69 
27. Zhang J, Ebraheim N, Li M, He X, Schwind J, Liu J, Zhu L,(2015) External fixation using locking plate in distal tibial fracture: a finite element analysis. Eur J Orthop Surg Traumatol 25:1099-1104. DOI 10.1007/s00590-015-1604-7

28. Bach AW, Hansen ST, Jr.,(1989) Plates versus external fixation in severe open tibial shaft fractures. A randomized trial. Clin Orthop Relat Res:89-94

29. Marti RK, van der Werken C,(1991) The AO-plate for external fixation in 12 cases. Acta Orthop Scand 62:60-62. DOI 10.3109/17453679108993094

30. Sun LJ, Wu ZP, Guo XS, Chen H,(2014) Management of distal third tibial fractures: comparison of combined internal and external fixation with minimally invasive percutaneous plate osteosynthesis. International orthopaedics 38:2349-2355. DOI 10.1007/s00264-014-2467-y

31. He X, Zhang J, Li M, Yu Y, Zhu L,(2014) Treatment of segmental tibial fractures with supercutaneous plating. Orthopedics 37:e712-716. DOI 10.3928/01477447-20140728-57

32. Zhang J, Ebraheim NA, Li M, He X, Liu J, Zhu L, Yu Y, Siddiqui S,(2015) External Fixation Using a Locking Plate: A Reliable Way in Treating Distal Tibial Fractures. J Orthop Trauma 29:e454-458. DOI 10.1097/bot.0000000000000377

33. Zhang J, Ebraheim N, Li M, He X, Liu J, Zhu L, Yu Y,(2015) External fixation using femoral less invasive stabilization system plate in tibial proximal metaphyseal fracture. Clin Orthop Surg 7:8-14

34. Liu W, Yang L, Kong X, An L, Hong G, Guo Z, Zang L,(2017) Stiffness of the locking compression plate as an external fixator for treating distal tibial fractures: a biomechanics study. BMC Musculoskelet Disord 18:26

35. Ang BFH, Chen JY, Yew AKS, Chua SK, Chou SM, Chia SL, Koh JSB, Howe TS,(2017) Externalised locking compression plate as an alternative to the unilateral external fixator: a biomechanical comparative study of axial and torsional stiffness. Bone Joint Res 6:216-223

36. Qiu XS, Yuan H, Zheng X, Wang JF, Xiong J, Chen YX,(2014) Locking plate as a definitive external fixator for treating tibial fractures with compromised soft tissue envelop. Arch Orthop Trauma Surg 134:383-388. DOI 10.1007/s00402-013-1916-1

37. Atif M, Mohib Y, Hasan O, Rashid H,(2020) In the cost-conscious era: Ilizarov circular frame or uniplanar external fixator for management of complex open tibia shaft fracture, retrospective cohort study from a level-1 trauma center. J Pak Med Assoc 70(Suppl 1):S20-S23

38. Tulner SA, Strackee SD, Kloen P,(2012) Metaphyseal locking compression plate as an external fixator for the distal tibia. International orthopaedics 36:1923-1927

39. Ahmad RA, Aithal HP, Madhu DN, Amarpal, Kinjavdekar P, Pawde AM,(2017) Use of locking plate in combination with dynamic compression plate for repair of tibial fracture in a young horse. Iran $\mathrm{J}$ Vet Res 18:138-141

40. Baloch SR, Rafi MS, Junaid J, Shah M, Siddiq F, Ata-Ur-Rahman S, Zohaib Z,(2020) Ilizarov Fixation Method of Tibia Plateau Fractures: A Prospective Observational Study. Cureus 12:e11277

\section{Figures}



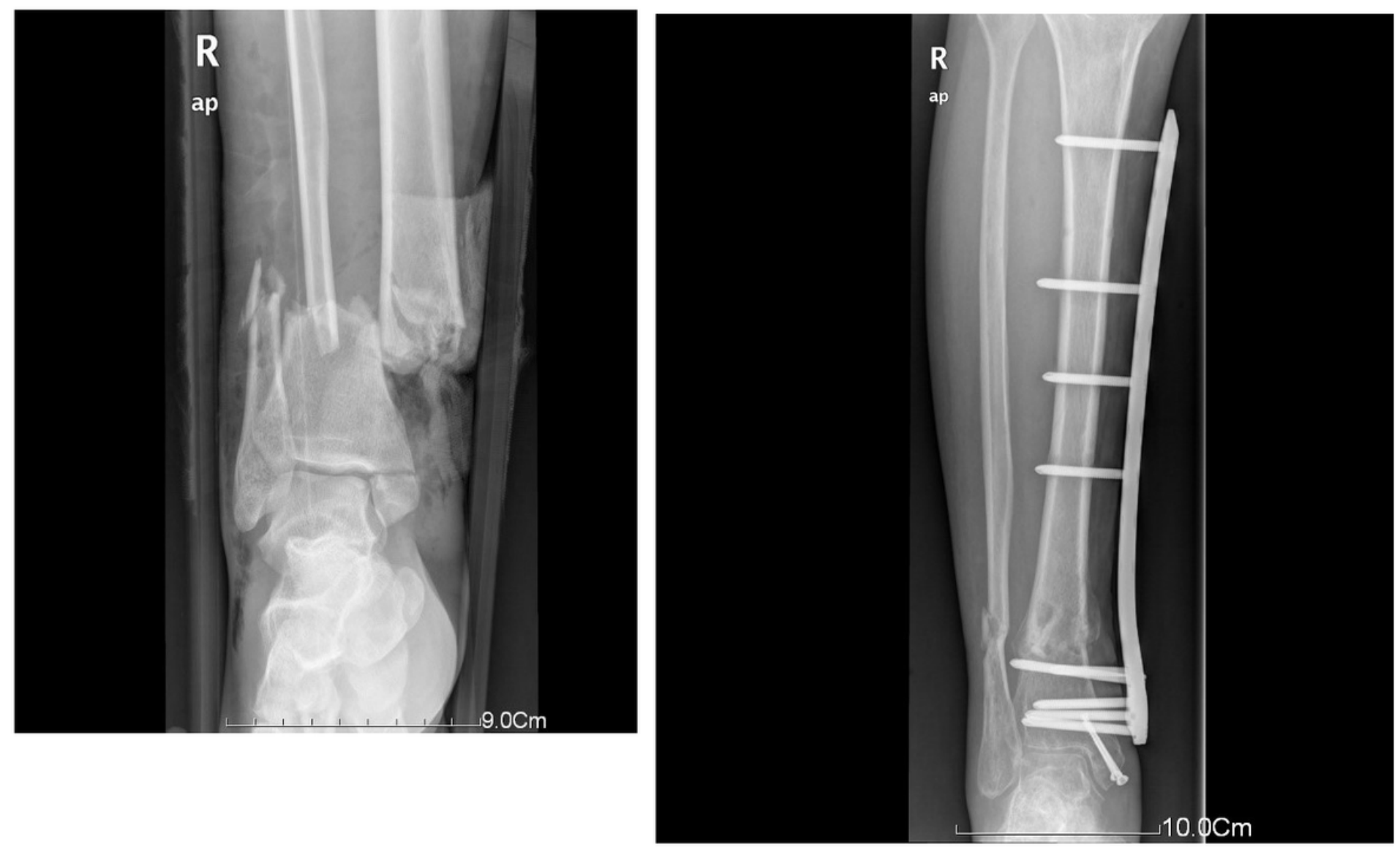

\section{Figure 1}

Anteroposterior X-ray films of a 48-year-old male patient with tibia fracture of the right (AO/OTA 43A2 type ) caused by falling from height. a,Before the operation, open fracture of distal $\nabla$ segment of the tibia; b, At 6 months after the operation, the fracture healing was good, and the external fixator with locking plate was in place.
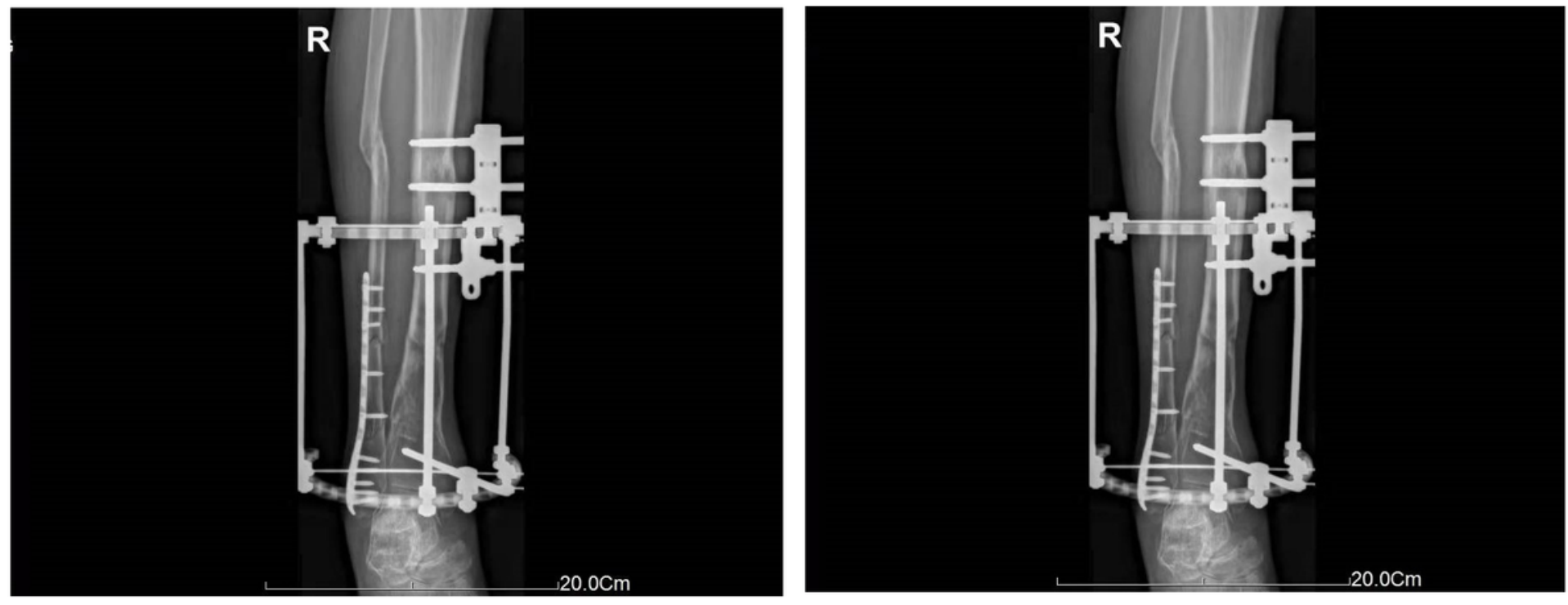

Figure 2 
Anteroposterior X-ray films of a 59-year-old male patient with tibia fracture of the right (AO/OTA 43A2 type ) caused by trauma. a, Before the operation, open fracture of distal $\triangle$ segment of the tibia; $b$, At 6 months after the operation, the fracture healing was good, and a circular external fixator was in place. 